\title{
Atenção primária à saúde e a construção de sentidos para a saúde bucal: leitura construcionista social sobre discursos de idosos
}

\author{
Primary healthcare and the construction of meanings of oral health: \\ a social constructionist interpretation of discourses of the elderly
}

\author{
Alexandre Favero Bulgarelli ${ }^{1}$ \\ Ione Carvalho Pinto ${ }^{2}$ \\ Carla Guanaes Lorenzi ${ }^{3}$ \\ Teresa Cristina Scatena Villa ${ }^{2}$ \\ Soraya Fernandes Mestriner ${ }^{4}$ \\ Rosalina Carvalho da Silva ${ }^{3}$
}

${ }^{1}$ Faculdade de Odontologia, Universidade Federal do Rio Grande do Sul. Rua Ramiro Barcelos 2492, Rio Branco. 90035-003 Porto Alegre RS. alefavbulg@yahoo.com ${ }^{2}$ Departamento de Enfermagem MaternoInfantil e Saúde Pública, Escola de Enfermagem de Ribeirão Preto,

Universidade de São Paulo.

${ }^{3}$ Faculdade de Filosofia,

Ciências e Letras de

Ribeirão Preto,

Universidade de São Paulo.

${ }^{4}$ Faculdade de Odontologia

de Ribeirão Preto,

Universidade de São Paulo.
Abstract Dentistry currently reveals itself to be open to new ideas about the construction of meanings for oral health. This openness leads to the social production of health revealing the contextualization of the social and historical aspects of the sundry knowledge in the development of oral health for different communities. With this research, we seek to build meanings for oral health with a group of elderly people. With this objective in mind, we propose an approximation between discourses on oral health mentioned by the elderly and the Social Constructionist discourse. We interviewed 14 elderly people enrolled in a Family Health Unit in Ribeirão Preto, State of São Paulo, in the first semester of 2010, and identified two interpretative repertoires through Discourse Analysis, which showed the relationship between 1 Lack of information and dental assistance in childhood, and 2 - Primary Health Care building the meaning of oral health. We concluded that Social Constructionism works epistemologically for the construction of meanings for oral health and that primary health is essential for appreciation and health care that enables the construction of meanings in oral health by the elderly that create conditions for self-care and healthy attitudes.

Key words Social constructionism, Oral health, Elderly, Primary healthcare
Resumo A odontologia mostra-se, na atualidade, aberta à construção de novos sentidos para saúde bucal. Esta abertura vem ao encontro da produção social da saúde e mostra a contextualização de aspectos sociais e históricos dos diversos saberes na construção da saúde bucal para as diferentes comunidades. O objetivo da presente pesquisa foi construir sentidos para a saúde bucal com um grupo de idosos. Nesta perspectiva, propôs-se uma aproximação entre os discursos sobre saúde bucal de idosos e o Construcionista Social. Assim, foram entrevistados 14 idosos cadastrados em uma Unidade de saúde da família na cidade de Ribeirão Preto/SP, no primeiro semestre de 2010, e identificados dois Repertórios Interpretativos, por meio da Análise de Discurso, que mostraram as relações existentes entre 1-Deficiência de informação e assistência odontológica na infância, e 2-Atenção Primária à Saúde construindo o sentido da saúde bucal. Concluiu-se que o Construcionismo Social vem colaborar epistemologicamente para a construção de sentidos para saúde bucal e que a Atenção Primaria à Saúde é essencial para a valorização e o cuidado com a saúde que permite a construção de sentidos para a saúde bucal por parte de idosos, gerando condições para autocuidado e atitudes saudáveis.

Palavras-chave Construcionismo social, Saúde bucal, Idosos, Atenção primária à saúde 


\section{Introdução}

A construção de sentidos para a saúde, com a colaboração de idosos, pode ser proveniente de um conjunto de aspectos sociais, culturais, de práticas discursivas, de uso da linguagem e emoções que são legitimadas em ações sociais. Nesta postura, acreditamos que os sentidos podem ser construídos por meio da interlocução de vários sujeitos, saberes, linguagens, conhecimentos e discursos e esta construção tem como espaço conversacional a Estratégia de Saúde da Família (ESF).

Quando fazemos uso do termo práticas discursivas corroboramos com Spink ${ }^{1}$, pois estas são práticas utilizadas para entender a produção de sentidos no cotidiano por meio da maneira como as pessoas posicionam-se em suas relações sociais. Dito de outra forma, uma prática discursiva é a maneira como nos posicionamos no mundo e construímos sentidos para os fenômenos que acontecem acerca do mesmo.

Para que esta construção aconteça nos fundamentamos no discurso Construcionista Social que traz ao cenário epistemológico a construção de conhecimentos científicos por meio da ideia de que a construção de sentidos sobre algo é entendida como resultante de ações conjuntas entres as pessoas ${ }^{2}$. Sentidos são, portanto, construções de valores, pensamentos e ações que acontecem nas relações sociais ao longo dos diversos momentos históricos em que vivemos ${ }^{2,3}$. O Construcionismo Social é uma maneira de produzir conhecimento, e enquadra o processo epistemológico como algo que as pessoas fazem juntas por meio de suas práticas sociais ${ }^{3}$. Para o discurso Construcionista Social, o sentido que o mundo tem é diferente de acordo com as relações que o constroem, e esta diferença está enraizada nas nossas relações sociais ${ }^{4,5}$.

Na saúde coletiva o elo de comunicação entre as pessoas e o sistema de saúde é a Atenção Primária à Saúde (APS). O qual ocorre pelo próprio fortalecimento da ESF no Brasil mostrando-se como uma potência para a mudança paradigmática de modelo de atenção em saúde que está transformando a realidade do acesso à mesma. Com finalidade de dialogar com esta estratégia, concordamos com Mendes ${ }^{6}$ que destaca o grande avanço do SUS e a relação com a ideia de que a ESF vem substituir um sistema piramidal hierárquico por um sistema de saúde onde haja uma integração horizontal de todos os seus serviços. E neste processo, poder existir um grau de institucionalização que ocupe espaços políticos, educacionais, espaços de representação populacio- nal e do próprio serviço de saúde. Assim, o espaço de representação populacional, vem estabelecer o valor da ESF, fazendo com que a população adscrita busque e adote medidas preventivas, de tratamento, de promoção e de recuperação da saúde, reconhecendo-se como sujeito de sua saúde e adotando práticas de autocuidado para satisfação com a própria saúde bucal ${ }^{6,7}$.

A ESF leva ao acolhimento, e nesta linha de entendimento destacamos Matumoto et al. ${ }^{8}$ que o retratam como resultado, após o acesso, das relações humanas no processo de atendimento. No encontro entre profissionais e usuário, acontece uma negociação produzindo um vínculo que visa a identificação de necessidades do usuário, uma busca pelo vínculo, com o objetivo de estimular a autonomia quanto à sua saúde.

Frente ao exposto, nos identificamos com o discurso de que a APS vai além da porta de entrada para o sistema de saúde ofertando serviços de tecnologia leves a uma população adscrita. Ela assume o papel de articuladora entre usuário e profissional, criando espaços conversacionais para a consolidação de uma corresponsabilidade, e para a construção de novos conhecimentos que atuam de maneira direta em um cuidado longitudinal.

\section{Objetivos}

Objetivamos com esta pesquisa construir sentidos para a saúde bucal com a colaboração de idosos. Esta construção acontece por meio de uma aproximação epistemológica com o discurso construcionista social, compreendendo possíveis relações dialógicas existentes entre o discurso de pessoas idosas cadastradas em uma Unidade de Saúde da Família na cidade de Ribeirão Preto (SP), o discurso da Atenção Primária à Saúde, bem como os contextos históricos e sociais da vida destas pessoas.

\section{Metodologia}

Esta é uma pesquisa de abordagem qualitativa, orientada teórica e metodologicamente pela perspectiva Construcionista Social. Selecionamos 14 idosos cadastrados em uma Unidade de Saúde da Família na cidade de Ribeirão Preto (SP). Trabalhamos com 14 idosos, pois utilizamos certos critérios de inclusão pertinentes para a pesquisa, visto que o universo populacional continha todas as pessoas com idade entre 65 e 74 anos ads- 
critas na referida unidade. Desta maneira, selecionamos apenas idosos orientados no tempo e espaço sem sugestão de demência e que não estavam acamados e/ou impossibilitados de participar da pesquisa. Seguindo tais critérios chegamos ao número de 14 idosos.

Todos os idosos estudados moravam com suas respectivas famílias, tinham origem rural e eram aposentados. Os dados foram coletados por meio de entrevistas semidirigidas seguindose um roteiro norteador contendo perguntas como: Você pode me contar alguma coisa que aconteceu com você que está relacionado com saúde bucal?; Quando você era criança como que se cuidava dos dentes?; E hoje em dia, como o $\mathrm{Sr}$ (a) cuida da saúde da boca?; Com o passar dos anos o que vem acontecendo com sua cavidade bucal?; O que o $\mathrm{Sr}(\mathrm{a})$ pensa sobre saúde bucal? As entrevistas foram realizadas no primeiro semestre de 2010, e os textos originários das transcrições - normas de transcrição segundo Preti $^{9}$ - foram submetidos à Análise de Discurso fundamentada em Repertórios Interpretativos.

A trajetória de análise foi composta de momentos como: Construção do corpus de análise, que por sua vez constituiu-se dos textos referentes às transcrições das entrevistas registrando toda a participação verbal dos entrevistados; Contato com a produção da pesquisa realizado com leituras iniciais flutuantes, e sequencialmente exaustivas, curiosas e reflexivas, buscando entrar no universo dos entrevistados e no contexto das entrevistas, e desta maneira aproximação com os temas dos discursos; Identificação dos Repertórios Interpretativos por meio do reconhecimento e agrupamento de imagens, adjetivos, expressões e figuras de linguagem (metáforas) presentes nos discursos dos entrevistados. Os repertórios interpretativos são sistemas de termos utilizados pelas pessoas em seus discursos para caracterizar e analisar ações, eventos e outros fenômenos $^{5,10}$. E finalmente a Construção da apresentação e discussão dos repertórios com a apresentação de fragmentos das falas dos idosos.

O presente estudo teve seu projeto de pesquisa submetido à Comissão de Ética em Pesquisa do Centro de Saúde Escola da Faculdade de Medicina de Ribeirão Preto, sendo o mesmo aprovado para realização na Unidade de Saúde da Família em questão, e a liberdade dos idosos foi aspecto imperativo para realização das entrevistas, sendo que as mesmas foram realizadas após assinatura do termo de consentimento livre e esclarecido conforme resolução 196/96 do Conselho Nacional de Saúde.

\section{Resultados e discussão}

$\mathrm{Na}$ dialogia entre os discursos dos idosos, sobre saúde bucal e aquele trazido pela APS, construímos os seguintes Repertórios Interpretativos: 1) Deficiência de informação e assistência odontológica na infância; 2) A Atenção Primária à Saúde na construção dos sentidos para a saúde bucal. Ao analisá-los, buscamos compreendê-los em suas práticas discursivas, entendendo e identificado suas existências, permanências e diversidades ${ }^{1,10}$. Estas duas construções interpretativas foram fundamentais para o entendimento e a compreensão das relações que envolviam a construção dos sentidos para saúde bucal presentes no discurso dos idosos entrevistados.

No processo dinâmico de construção de um conhecimento sobre saúde bucal, nos apropriamos da perspectiva construcionista social, pois a mesma sugere certos contextos norteadores que derivam de relações coordenadas que produzem o nascimento de uma linguagem que adquire capacidade para proporcionar inteligibilidade às pessoas em seus contextos ${ }^{4,5}$. A grande questão construcionista é olhar para o processo que dá sentido a algo juntamente com outros. Este processo conjunto de construção de sentidos deriva do olhar para o discurso, aprender e negociar com outros sujeitos, obtendo sucesso em uma comunicação tentando entender estes outros sujeitos. Este é um processo em que se compartilha saberes $^{4,5}$.

Pensamos que o fato de compartilhar saberes está diretamente associado ao fato de olharmos para a linguagem que se estrutura em uma conversa dialógica. A linguagem a que nos referimos é aquela proveniente do contexto e da maneira como a interação social entre diversas pessoas é guiada e coordenada para a construção de algo. Para este processo é fundamental a comunicação refletida na utilização de linguagens. Assim, este nosso pensamento vem ao encontro de Lefèvre $^{11}$, que destaca que diversos termos, expressões e metáforas, podem ajudar a compreender aspectos relevantes dos sentidos para o processo saúde doença em nossas vidas.

Focando nas possíveis relações entre pessoas idosas e saúde bucal, certas ações coordenadas permitiram uma retórica para conversar com os idosos sobre saúde bucal e entender as diversas relações existentes. Estas conversas nos possibilitaram identificar e entender diversas relações que compõem a saúde bucal e deste modo trabalhamos os dois Repertórios Interpretativos. Assim, esses repertórios mostraram ao longo da análise, 
o caminho que nos levou a compreender a saúde bucal conversando e interagindo com idosos.

\section{Deficiência de informação e assistência odontológica na infância}

O primeiro espaço para análise surgiu no momento em que os idosos mostraram suas histórias de vida. Nestas ricas histórias pudemos entender que muitas situações permitiram agrupar várias falas de maneira que a falta de informação e de assistência odontológica na infância foram o ponto de partida para que a preocupação com a saúde bucal para estes idosos começasse a ocupar espaço na fase adulta de suas vidas. Desta maneira, a relação que existe entre as histórias de infâncias sem cuidado materno e/ou familiar e a atual condição da cavidade bucal é uma relação de deficiência frente à informação e à assistência odontológica.

[Entrevistador] então esse episódio que a senhora falou... né... tava mastigando e a ponte saiu.. o que você sentiu em relação a isso ai? A senhora até deu uma risadinha né... mas o que você pensa em relação a isso?

[Entrevistado] eu penso que se eu tive sido... me falado desde criança éh... tivesse conhecimento... de escovar dente... de usar fio dental... de limpeza da boca como que tem hoje.. talvez não tivesse perdido os dentes.. e ter que fazer ponte... ter dente estragado... porque meus pais não me ensinaram... mesmo quando era mocinha... não me incomodava... porque hoje tudo é muito mais esclarecido... desde pequenininho já começa a ensinar as crianças... na minha época nada disso me aconteceu... eu acho que se tivesse nascido agora não passaria por esse vexame de ter perdido a prótis no meio do povo... [Trecho 1]

[Entrevistador] hoje em dia...... a senhora fala pra ela (neta) fazer as coisas que a senhora acha que é certo em relação o boca?

[Entrevistado] é isso mesmo... dô um oriento pra ela... por que eu num tive... ah... sei lá... na hora não me vem muita coisa pra falar... então tem que escovar muito bem os dentes se não dá bichinho... eu até já falei pro meu outro neto quando ele era menorzinho... ele falava assim... ah... vó... hoje não vou escovar o dente...porque criança tem isso... eu falava não... você precisa escovar os dentes senão dá bichinho forma buraquinho no dente tal.. e coisa... acaba com o dentinho e dói... já passei por isso meu filho...

[Entrevistador] Isso é uma coisa que a senhora quando era criança não teve?

[Entrevistado] é...... orientação que se diz... não tive... se tivesse... hoje eu estava com meus dentes todos... por isso tenho protis... [Trecho 2]
Estas falas estão presentes em um processo destacando o relato de experiências desagradáveis vividas com próteses dentárias como consequência da deficiência de assistência odontológica na infância. Ou seja, a consequência vivida justifica-se pela ausência de cuidado em fases anteriores da vida destes idosos. Observamos no Trecho 2, que o idoso mostrou em seu discurso que como não teve orientação sobre cuidados com a saúde bucal, seja esta informação de qualquer origem, afirmou que na atualidade possivelmente teria todos os dentes. Isto deixa clara a ideia de que na atualidade este idoso é informado sobre a prevenção e os cuidados com a saúde bucal. Neste processo, observamos que não existe uma relação de culpa aos pais, mas sim ao macro-contexto de suas histórias de vida (infância e adolescência) onde não se falava de cuidado com a saúde bucal. O cenário de deficiência de informação e não preocupação com a saúde da boca reflete o sentido da saúde bucal para saúde pública brasileira da época. Na referida época, em que estes idosos eram crianças, em meados das décadas de 40 e 50, a saúde bucal ficava a margem da preocupação com saúde da população, pois a saúde pública focava sua atenção em doenças de ordem infecto-contagiosas priorizando um contexto sanitário campanhista com a prevenção de doenças que emergiam no Brasil ${ }^{12}$. A falta de assistência e de cuidados odontológicos na infância destes idosos era consequência do modelo curativista e discriminador que havia no país nestas décadas.

Entendemos que existe uma relação direta entre informação, cuidado (prática) e consequência, pois esta relação aflorou no momento em que o idoso relatou que se tivesse tido informação anterior teria cuidado dos dentes e, consequentemente, evitado um vexame. $\mathrm{O}$ qual entendemos como um momento de sua história de vida que o deixou em situação social desconfortável, visto que a saúde bucal também é fator determinante de relações sociais, e o fato de ficar sem dente na presença de outros reduzem as pessoas e faz com que as mesmas se sintam excluídas socialmente. Esta relação entre saúde bucal e exclusão social está presente na nossa sociedade ${ }^{12}$.

A relação de informação e cuidado também esteve presente em outros momentos:

[Entrevistador] então por exemplo... quando a senhora era criança... dentro da casa da senhora não tinha escova de dente... e nem sabia que existia o dentista...

[Entrevistado] nem sabia que existia escova de dente... nunca tivemos naquela época uma escova de dente.... se pensava em lavá os pé e tomá 
banho... não pensava no dente... por que o dente é uma coisa que quando era criança ia perder mesmo... nasce outro... e depois se aparecia uma cári, cári né?... Ia no dentista da cidade ou tratava ou arrancava o dente.. era isso que fazia na época... [Trecho 3]

$\mathrm{Na}$ fala contida neste trecho (Trecho 3) da entrevista o cuidado com os dentes na infância não era incluído nem mesmo nos cuidados mínimos de higiene que esse entrevistado tinha na época. Ou seja, a saúde bucal não tinha sentido no contexto de higiene pessoal. Este entrevistado, de origem rural e baixa escolaridade, quando mostrou que não se pensava no dente, entendemos que esta era uma generalização onde a expressão "se pensava" é uma maneira de incluir toda uma geração de crianças e familiares da época. Outro contexto interessante é o fato de existir na época uma relação de despreocupação com os dentes decíduos visto que era uma situação real a ausência de importância dada a tal dentição, visto que, a mesma seria substituída por dentes permanentes.

Esta despreocupação, relacionada com a falta de informação destas pessoas neste período de suas vidas, permitia a construção de uma prática social que segundo $\mathrm{McNamee}^{13}$ e Gergen ${ }^{14}$ pode ser trabalhada por meio de conversas, experiências e informações que eram negociadas entre os sujeitos sociais que passavam por este processo.

Burr $^{3}$ mostra que as pessoas ao negociarem formas de conhecer o mundo, negociam também formas de agir sobre ele. Este pensamento vem ao encontro do sentido identificado até este momento, visto que negociações feitas com situações passadas de informação e cuidado com a saúde bucal criaram condições para a construção de maneiras de agir que mostram sentidos, pensamentos e atitudes presentes vida destes idosos.

Em outros trechos destacamos:

[Entrevistador] quando a senhora era criança... assim... como que era? as pessoas falavam que tinha que cuidar dos dentes... ou não?

[Entrevistado] não.. o pessoal era muito simples né... não tinha aquela preocupação com a saúde da boca... vixi... agora, hoje em dia as mães já levam dêusde pequeno no dentista... cuida melhor... fala que tem que escová... escova deusde pequenininho... de primeiro as mães nem ligava pra isso... e tinha aquilo de tinha uma dorzinha no dente ia lá... nem... nem.... quando vê já tinha tirado o dente...eh..... não era só isso... dava dor de dente as mães fazia aquele emplasto de fubá quente e punha assim... na gente... (entrevistado coloca a mão no rosto simulando o local)
[Entrevistador] ahh é? e punha pro lado de fora?

[Entrevistado] é... a gente sofria muito quando era criança de dor de dente... [Trecho 4]

[Entrevistador] como é que era aquela época que a senhora era mais nova?

[Entrevistado] ah a gente num ligava muito não... minha mãe não dava de cima da gente pra gente escová os dente... num ligava pra escová...... comia num limpava... vô tê falá que num ligava pra escová dente não... acho que é por isso que estragô muito meus dente... não tinha uma orientação...... não não não... igual hoje em dia que os pais dá de cima dos filhos... leva nos dentistas... (pai fala) você precisa começar ir no dentista você precisa cuidá dos dente... vamo no dentista... antigamente não era isso não... mas eu vejo que eu to na média do pessoal que eu vejo da minha idade... tô bem... [Trecho 5]

As expressões destacadas nos trechos acima nos convidaram a pensar mais uma vez na falta de preocupação que existia com a saúde bucal. Quando o entrevistado verbalizou que de primeiro as mães nem ligavam pra isso, e se utiliza da metáfora "não dava em cima da gente", entendemos que na época em que o entrevistado era crianças sua mãe não se preocupava com a saúde da boca e consequentemente não passava esta cultura de cuidado com a saúde bucal para os filhos. No trecho 4 ficou evidente a comparação que o entrevistado, expressando certo entusiasmo e euforia que observamos na expressão vixi, fez entre sua condição de falta de informação na infância e o cuidado percebido na atualidade onde o acesso à informação, à assistência e ao cuidado com a saúde bucal é real e presente no nosso diaa-dia. Esta comparação estabelece uma relação social de acesso a estes aspectos, seja pela proximidade com o serviço ou pela informação e educação em saúde ${ }^{15,16}$.

Esta era a realidade dos discursos provenientes da vida diária destes idosos, e neste contexto Berger e Luckmann ${ }^{17}$ destacaram que a realidade, que cerca os membros de uma sociedade, comunidade ou grupo social, é que direciona condutas subjetivas dotadas de sentidos construídos socialmente que originam pensamentos e ações.

Ao compreendermos o sentido para a saúde bucal proveniente da deficiência de informação e de assistência odontológica na infância, corroboramos com Beauvoir ${ }^{18}$ que vem ao encontro deste estudo, mostrando que o passado, o presente e o futuro estão intimamente relacionados ao longo de toda a existência dos seres humanos, e que as associações e as relações que fazemos ao 
longo de nossa vida refletem-se na relação que o passado tem com o presente e com a maneira peculiar que cada um envelhece.

\section{A Atenção Primaria Saúde construindo o sentido da saúde bucal}

Um dos aspectos mais relevantes da construção dos sentidos para a saúde bucal com os idosos entrevistados foi a contextualização frente à Atenção Primária à Saúde que possibilitou a identificação do presente repertório interpretativo. Referimos-nos à ação da ESF nas vidas cotidianas destes idosos por meio de uma conversa dialógica entre seus conceitos e premissas, e os discursos trazidos pelos idosos expressos nas suas entrevistas. Quando olhamos para estes idosos e vemos que todos eles vivenciavam no seu dia-adia o cuidado provido pela ESF, pudemos de certa maneira identificar alguns conceitos que se relacionaram diretamente com práticas e cuidados para a construção dos sentidos para a saúde bucal.

A aproximação entre a APS e a construção de sentidos para a saúde bucal é refletida no conceito de coletividade, compartilhando suas ações olhando para o coletivo e não para o indivíduo. Para tanto, retomarmos Gergen ${ }^{4}$, pois, segundo este autor, são as relações existentes nos mais variados contextos - sociais, culturais e históricos - que tornam possíveis a construção de sentidos sobre algo. Há uma mudança no pensamento dos idosos frente ao cuidado e à assistência à saúde visto que diversos aspectos de suas vidas eram rodeados por situações em que a APS proporcionava a promoção de saúde por meio das ações do SUS. A participação do SUS na construção de sentidos para a saúde bucal foi perceptível nos trechos a seguir:

[Entrevistador] nossa oito? que beleza heim... se a senhora tivesse que explicar para um netinho da senhora... pegasse um neto da senhora... e tivesse que falar pra ele o quê que é saúde da boca... o quê a senhora falaria pra ele?

[Entrevistado] saúde bucal é cuidar né... por que hoje tem a mãe também né... a mãe que orienta né... tudo eles tem o dente bonito... dente bom... eu falaria que saúde da boca... éh... tem que cuida né... tem que escova os dente né... no dia que fui tomá vacina no Núcleo aqui perto eu vi o dentista falando pra mãe da criança que tinha que fazê o filho escova o dentinho... - fui tomá vacina da gripe sabe... é bom... [Trecho 6]

No texto acima (Trecho 6), a integralidade da atenção aflorou na realidade deste idoso no momento em que a conversa entra em uma dinâmi- ca sobre o cuidado. Mais uma vez o cuidado esteve presente na construção de sentidos para a saúde bucal, porém, neste tempo curto, como diz Spink ${ }^{19}$, de interação e dialogia, o cuidado com a saúde geral é explícita na busca pela prevenção de doenças como a gripe. A ação coletiva de prevenção de campanhas de vacinação propostas pelo SUS, fez com que este idoso fosse indiretamente informado sobre a importância da mãe no cuidado com a saúde bucal da criança. Esta informação ocorreu em um espaço promotor de saúde que é o SUS. De encontro a presente pesquisa, Mendes ${ }^{20}$ mostra que a aplicação da integralidade é o reconhecimento de que a APS envolve ações de promoção, prevenção e reabilitação, de maneira integrada, onde as intervenções englobam as pessoas e suas inter-relações com seus ambientes natural e social.

No momento em que identificamos a fala no dia que fui tomá vacina no Núcleo aqui perto eu vi o dentista falando pra mãe da criança que tinha que fazê o filho escová o dentinho mostrando-se repleta de ações e sentidos, pudemos entender a relação entre fácil acessibilidade à assistência e integralidade da atenção, visto que, esta relação de proximidade entre cuidar da gripe perto de casa e informação sobre saúde bucal, observando as ações na Unidade de saúde, representa uma integralidade de saberes quando o assunto é promover saúde. Entendemos, neste contexto, a integralidade como o atributo das práticas em saúde que proporciona o cuidado holístico e integral da interlocução de diferentes práticas como as médicas, de enfermagem e odontológicas, dentre outras ${ }^{14,21}$.

Seguindo esta linha de pensamento, identificamos outros momentos da entrevista que, além de nos convidarem a pensar a integralidade e a multidisciplinaridade para a construção de sentidos para a saúde bucal, caracterizam outro conceito que está relacionado com uma diretriz organizativa que é a referência e a contrarreferência entre os serviços. Este conceito esteve presente no discurso destacado no trecho 7.

[Entrevistador] ali na (Rua) Martinico Prado tem muito dentista né?

[Entrevistado] tem mesmo... muito... mas como tava te falando... depois como tenho diabete... aí... eu tratava com a liga da diabete no posto aqui em cima (gesto com a mão apontando a direção do posto) então falaram do dentista também e me mandaram pra ele... por que todas pessoas que tem diabete eles mandam pro dentista... pra cuida dos dente e da boca e da gengivi... aí então desde aquela época fui primeiro no dentista do núcleo e agora tô cuidando aqui no posto. [Trecho 7] 
A possibilidade de conversar reflete a construção de uma realidade de processos conversacionais que, por sua vez, geram práticas e ações sociais $^{2,4}$. Foi nesta possibilidade de falar sobre a presença fácil de dentistas que a associação feita entre os cuidados com a diabetes e com a saúde bucal emergiu no discurso no momento em que o encaminhamento de usuários diabéticos para a assistência odontológica é vivenciado com usuários do SUS na específica unidade de saúde. Acreditamos que a relação entre a assistência odontológica e o cuidado com a diabetes possibilitou a conversa entre estas práticas e desta forma permitiu a construção de valores para a saúde bucal que se refletem nas atitudes dos idosos em procurarem o dentista para cuidar da saúde dos dentes e da gengiva, tendo como elo a APS.

A referência e a contrarreferência são diretamente responsáveis pela longitudinalidade e pelo acolhimento do paciente, visto que ao se trabalhar com diferentes contextos e níveis de atendimento, a APS tornou-se fundamental como instrumento de organização de um sistema de saúde que tem como premissas a integralidade e a universalidade ${ }^{15}$.

Quando os discursos conduziram ao conceito de acolhimento destacamos o trecho 8 .

[Entrevistador] é... bom assim quando cuida da boca... não é?

[Entrevistado] é...... que nem... agora o dentista que eu fui aqui no posto me fala as coisa... fala que no máximo agora... principalmente quanto mais (a pessoa) velha vai ficando... os anos vai passando... então vai murchando (a gengiva)... entende... ela (dentadura) não vai ficando bem assentadinha... no máximo é cinco seis anos mesmo... vai murchando a..... maxilar que fala? o maxilar e a gengiva... é a gengiva... isso mesmo... justo... (entrevistada aponta com o dedo da mão o local referido) [Trecho 8]

Este trecho da entrevista (Trecho 8), realizada com um idoso autônomo, independente e ativo, e contextualizada em um momento em que a conversa desenvolvia-se sobre características do envelhecimento da cavidade bucal, nos sensibilizou a identificar, no repertório interpretativo em questão, expressões e falas que mostraram a associação entre a importância do dentista de uma unidade de saúde (dentista trabalhador do SUS) e o acesso à informação sobre a saúde bucal. Esta dialogia proporciona negociações sobre a temática conversada e assim novas relações e sentidos sobre algo são construídas ${ }^{4}$. A fala agora... o dentista que eu fui aqui no posto me fala as coisa tem a função, dentro deste discurso, de pontuar a existência de comunicação entre o usuário e o dentista, de modo que esta comunicação é instituída como sentimento de ser acolhido a partir do momento em que é informado sobre saúde bucal.

Quando destacamos o acolhimento, pensamos em humanização de atendimento e tudo isso remete à ESF. Entendemos que a construção dos sentidos para a saúde bucal com estes idosos, não seria conduzida desta maneira caso não houvesse a implantação da referida estratégia no local onde a pesquisa foi desenvolvida.

O vínculo é muito importante, pois por meio dele o sistema de saúde caminha dentro das prerrogativas do SUS e confere práticas conversacionais que promovem o conhecimento das necessidades da população assistida ${ }^{22}$. Estas práticas conversacionais são realizadas por processo dinâmico de relacionamento interpessoal entre funcionários e/ou entre funcionários e usuários, especificamente por visitas domiciliares provenientes da perspectiva da estratégia de saúde da família ${ }^{23}$. Desta maneira destacamos:

[Entrevistador] o que é saúde bucal pro senhor?

[Entrevistado] ah... saúde bucal o que eu te digo? em termos do que é bom eu acho que é muito importante o cuidado... cuidá em casa... eles (agentes comunitárias de saúde) vem aqui em casa... eles orientam a gente direitinho é muito bom... é sempre estar indo procurar também né... e fazêe exames também porque precisa... saúde bucal é uma higiene... uma higiene né... a pessoa tem que faze como se fosse qualquer outra coisa... tomá banho fazê o que for...porque com o corpo a boca ainda é muito mais importante mais sério ... [Trecho 9]

Os trechos acima destacados foram de fundamental importância para que pudéssemos entender a relação da saúde bucal com as visitas domiciliares dos agentes comunitários de saúde. As visitas domiciliares são práticas fundamentais que norteiam a ESF de maneira que funções de vigilância em saúde como o diagnóstico populacional, a identificação de riscos em saúde, bem como o vínculo, a capacidade de escuta e o acolhimento, estejam relacionados com a construção de sentidos para a saúde da boca ${ }^{15}$.

A construção de sentidos para a saúde bucal deve-se ao fato de que os idosos se cuidam tendo como orientação as informações provenientes da ESF e desta maneira os agentes comunitários de saúde são sujeitos sociais fundamentais nesta orientação e educação para a saúde. No trecho 9 quando o idoso expõe vem aqui em casa..., identificamos nesta proposta uma fala que mostra o agente comunitário como acolhedor no sentido de pes- 
soa que tem o cuidado humanizado de explicar e conversar sobre determinados cuidados com a saúde. Esta humanização do atendimento é fundamental dentro da estratégia de saúde da família para que vínculos sejam criados com a comunidade. Assim, corroborando com Camargo-Borges ${ }^{24}$ estes vínculos entre serviço e usuário negociam, dentro da realidade da comunidade, propostas de cuidado com a saúde de maneira que sua promoção seja o eixo condutor desta dialogia.

É interessante a presença de os agentes comunitários na vida destes idosos, pois os mesmos influenciam diretamente na construção de sentidos para a saúde bucal. Os agentes, nessa condição de promotores de saúde, criam um vínculo dentro de uma relação de confiança que gera condições para que a educação em saúde seja o elo entre a APS e os sentidos para a saúde bucal.

Neste contexto destacamos o estudo de Koyashiky et al. ${ }^{25}$, pois tais autores mostraram, por meio da análise dos discursos de agentes comunitários de saúde, que estes profissionais entendem a saúde bucal como algo muito importante e que podem pensar e agir para transformar a realidade da saúde das pessoas. Segundo os mesmos autores, o agente comunitário de saúde é um dos profissionais responsáveis por tornar real a ideia de que saúde bucal significa educar e promover mudanças de hábitos por meio da promoção da saúde ${ }^{25}$.

Quando permitimos que o idoso mostrasse a origem de seu conhecimento sobre o cuidado com a saúde bucal identificamos no trecho 9 um conjunto de expressões e falas que, caracterizando o repertório interpretativo construído, tiveram a função, dentro do discurso em questão, de justificar a relevância da equipe de saúde da família, e mais amplamente a APS, como promotoras de conhecimento em saúde bucal. $\mathrm{O}$ qual, muitas vezes, é foco de condições que fazem com que os idosos atentem-se ao autocuidado em casa. Na fala ...cuidá em casa... eles (agentes comunitários de saúde) vem aqui em casa... eles orientam a gente direitinho, é muito bom, identificada no trecho 9, os vocabulários nos levaram a entender que esta é uma relação de cuidado muito estreita e importante para estes idosos, deixando claro a aceitação dessa visita para que os idosos se sintam cuidados, assistidos e responsáveis por suas saúdes bucais. Esta responsabilidade deve-se à relação de valorização da informação para o autocuidado. Neste sentido, o cuidar em saúde extrapola os muros da Unidade de Saúde da Família e passa a ser vivenciado dentro das residências de cada idoso, e este fato os transformou em autocuidadores de suas saúdes bucais. Este discurso nos levou a entender que o cuidar em casa (autocuidado) foi possível a partir do momento em que a importância da saúde bucal entrou nas casas destes idosos.

De certa maneira, entendemos que a função do repertório em questão foi transmitir a ideia de que educação em saúde bucal faz parte de contextos que permitem a construção de sentidos para a saúde bucal. Falar de saúde bucal neste sentido é contextualizar o dentista como agente educador em saúde tendo como cenário desta educação o espaço conversacional criado pela ESF.

\section{Considerações finais}

A "conversa" entre Estratégia de Saúde da Família e Construcionismo Social foi a interlocução necessária entre os discursos dos idosos e o metodológico, para se estabelecer as relações dialógicas para a construção de sentidos para a saúde bucal com a colaboração de idosos. Com este estudo foi possível estabelecer, epistemologicamente, que a Atenção Primaria à Saúde, juntamente com o saber, pensar e agir das pessoas idosas, constrói cuidados e atitudes perante a saúde bucal.

$\mathrm{O}$ aspecto que consideramos relevante foi o espaço conversacional proporcionado pela Estratégia de Saúde da Família, pois este foi o espaço responsável pelo acesso que tivemos aos colaboradores. Esta aproximação só foi possível porque as pessoas idosas eram frequentemente visitadas por agentes comunitários e sentiam-se acolhidas pelo referido serviço de saúde. Consideramos então que a Atenção Primaria à Saúde, na condição de articuladora entre pesquisadores, profissionais, usuários e serviços de saúde, foi crucial para o desenvolvimento desta pesquisa, pois é lá que existem os espaços que permitiram e permitem as negociações entre saberes, valorização e aplicabilidade de ações de promoção da saúde e de educação em saúde.

Portanto, entendemos que os idosos participantes, inseridos em seus macro-contextos e coconstruindo os sentidos para a saúde bucal, parecem se articular em torno de discursos produzidos historicamente e ainda circulantes em nossa sociedade, promovendo aspectos em relação à saúde bucal. Porém, mesmo vivenciando situações consequentes do passado, estes idosos tornaram-se cuidadores de suas saúdes bucais e preocupados com o futuro. 


\section{Colaboradores}

AF Bulgarelli, IC Pinto, CG Lorenzi, TCS Villa, SF Mestriner e RC Silva participaram igualmente de todas as etapas de elaboração do artigo.

\section{Referências}

1. Spink MJP. Práticas discursivas e produção de sentidos no cotidiano, aproximações teóricas e metodológicas. 3a ed. São Paulo: Cortez; 2004.

2. Mcnamee S. Social construction as practical theory: lessons for practice and reflection in psychotherapy. In: Pare D, Larner G, editors. Collaborative practice in psychology and therapy. New York: Haworth Press; 2004. p. 9-21.

3. Burr V. An introduction to social construcionism. $2^{\text {nd }}$ ed. London: Routledge; 2003.

4. Gergen, KJ. Realities and relationships. Soundings in social constructions. $3^{\text {rd }}$ ed. Boston: Harvard University Press; 1997.

5. Gergen KJ. An invitation to social construction. $2^{\text {nd }}$ ed. Washington: Sage; 2009.

6. Mendes EV. A Atenção Primária à Saúde no SUS. Fortaleza: Escola de Saúde Pública do Ceará; 2002.

7. Bulgarelli AF, Manco ARX. Idosos vivendo na comunidade e a satisfação com a própria saúde bucal. Cien Saude Colet 2008; 13(4):1165-1174.

8. Matumoto S, Mishima SM, Pinto IC. Saúde coletiva: um desafio para a Enfermagem. Cad Saude Publica 2001; 17(1):233-241.

9. Preti D. Análise de textos orais. Projeto de estudo da norma linguística urbana culta de São Paulo: Projeto NURC/SP. São Paulo: FFLCH/USP; 1993.

10. Íñiguez L. Manual de análise do discurso em ciências sociais. 2a ed. Petrópolis: Vozes; 2004.

11. Lefèvre F. Mitologia Sanitária: saúde, doença, mídia e linguagem. São Paulo: Edusp; 1999.

12. Narvai PC, Frazão P. Saúde bucal no Brasil muito além do céu da boca. São Paulo: Editora Fiocruz; 2008.

13. McNamee S. O discurso construcionista social. In: Guanaes C, organizadora. A construção da mudança em terapia de grupo: um enfoque construcionista social. São Paulo: Vetor; 2006. p. 19-52.

14. Gergen KJ. The social constructionist movement in modern psychology. Am Psychol 1985; 40(1):266-275.

15. Starfield B. Primary care: balancing health needs, services and technology. Oxford: Oxford University Press; 1998.
16. Bastos JRM, Peres SHCS, Ramires I. Educação para a saúde. In: Pereira AC, organizador. Odontologia em saúde coletiva, planejando ações e promovendo saúde. Rio de Janeiro: Artmed; 2003. p. 117-139.

17. Berger PL, Luckmann T. A construção social da realidade. Petrópolis: Vozes; 2002.

18. Beauvoir SD. A velhice. $2^{\text {a }}$ ed. Rio de Janeiro: Nova Fronteira; 1990.

19. Spink MJP. Psicologia social e saúde, práticas, saberes e sentidos. 4a ed. Petrópolis: Vozes; 2007.

20. Mendes EV. Uma agenda para a saúde. $2^{\text {a }}$ ed. São Paulo: Hucitec; 2006.

21. Trezza MCAF, Santos RM, Leite JL. Enfermagem como prática social: um exercício de reflexão. Rev. Bras. Enferm. 2008; 61(6):904-908.

22. Teixeira R. O acolhimento num serviço de saúde como entendido como uma rede de conversação. In: Pinheiro R, Mattos RA, organizadores. Construção da integralidade. Cotidiano, saberes e práticas em saúde. Rio de Janeiro: Instituto de Medicina Social da Universidade do Estado do Rio de Janeiro, Abrasco; 2003. p. 89-112.

23. Pinto IC. Os sistemas de informação em atenção primária à saúde como instrumento de gestão em saúde: análise de experiências no Brasil e na Espanha[tese]. Ribeirão Preto: Universidade de São Paulo; 2008.

24. Camargo-Borges C. O construcionismo social no contexto da estratégia da saúde da família: articulando saberes e práticas [tese]. Ribeirão Preto: Universidade de São Paulo; 2007.

25. Koyashiky GAK, Alves-Souza RA, Garanhani ML. O trabalho de Agentes Comunitários de Saúde em Unidades de saúde da família. Cien Saude Colet 2008; 13(4):1343-1354.

Artigo apresentado em 25/03/2011

Aprovado em 15/05/2011

Versão final apresentada em 02/06/2011 